\title{
FENOMENOLOGIJA, PSIHOPATOLOGIJA \\ I FENOMENOLOŠKA \\ PSIHOPATOLOGIJA
}

\section{Stefan Jerotic ${ }^{1}$, Maja Pantović-Stefanovićc ${ }^{1,2}$}

1 Klinika za psihijatriju, Univerzitetski klinički centar Srbije, Beograd, Srbija

2 Medicinski fakultet, Univerzitet u Beogradu, Beograd, Srbija

doi: 10.5937/engrami42-32891 prispelo: 24.06 .2021 . prihvaćeno: 20.08 .2021 . objavljeno onlajn: 30.08.2021.

\section{Sažetak}

Uočavanje i definisanje strukture psihopatoloških pojava predstavlja osnov kliničke psihijatrije. Fenomenologija predstavlja grupu filozofskih principa koji su posvećeni sistematskoj analizi svesti i objekta svesti. Primena fenomenologije na psihopatološke pojave se naziva fenomenološka psihopatologija. Cilj fenomenološke psihopatologije je razjašnjavanje forme svesnog, doživljenog psihopatološkog iskustva. Upotreba fenomenološkog metoda omogućava razotkrivanje naizgled nepostojanih ili zanemarenih psihopatoloških pojava, kao i sistematičnu izgradnju psihopatološke taksonomije. U radu su definisiane i obrađene sledeće teme:

(1) fenomenologija kao skup filozofskih doktrina;

(2) fenomenološka psihopatologija, kao i njena primena u kliničkom radu;

(3) značaj Karla Jaspersa za fenomeno- 
lošku psihopatologiju i psihijatriju uopšte;

(4) savremene putanje fenomenološke psihopatologije.

Podrobno razumevanje koncepta fenomenološke psihopatologije predstavlja preduslov za precizno razumevanje subjektivnog iskustva pacijenta u psihijatriji.

Ključne reči: fenomenologija, psihopatologija, Karl Jaspers

\section{IZJAVA O KONFLIKTU INTERESA}

Ne postoji konflikt interesa.
Postupak uočavanja psihopatoloških fenomena koji su prisutni u određenom trenutku, kod određene osobe, predstavlja osnov susreta između kliničara i pacijenta u psihijatriji. U kliničkom smislu, imenovanjem i grupisanjem psihopatoloških pojava, operacionalizujemo ove elemente, koji nam na taj način omogućavaju da donesemo konkretne kliničke odluke. Uz pomoć ovog postupka, krećemo se duž putanje definisane od strane savremenih nozoloških sistema kako bismo "postavili dijagnozu", a nakon toga i primenili specifičan terapijski protokol za lečenje (ili prevenciju) psihičkog poremećaja. Način na koji pristupamo opisivanju i tumačenju pacijentovog doživljaja, kao i način na koji definišemo šta je to psihopatološka pojava se, između ostalog, zasniva i na određenim filozofskim pretpostavkama. Kako bi poboljšali jasnoću sagledavanja doživljaja pacijenata, kao i kritičko razmišljanje o navedenim doživljajima, neophodno je da svesno preispitamo i razjasnimo pretpostavke na kojima počiva postupak zaključivanja o psihopatološkim doživljajima kod naših pacijenata. Navedeno se delimično može postignuti kroz pojašnjenja koja se odnose na fenomenologiju i primenu fenomenološkog postupka na psihopatologiju, koji predstavlja osnov psihijatrijske dijagnostike i eksploracije psihičkog života pacijenta. 


\section{ŠTA JE}

\section{FENOMENOLOGIJA?}

Fenomenologija je reč koja vodi poreklo iz staro-grčkog jezika, nastala od reči phainomenon (pojava) i logos (nauka), a u bukvalnom prevodu označava "nauku o pojavama". Međutim neophodno je detaljnije odrediti pojmove: šta je zapravo fenomen?

Fenomen predstavalja način na koji se određena pojava prikazuje u ljudskom iskustvu. Pojava (objekat, predmet razmatranja) može se prikazati u iskustvu u gotovo beskrajnom varijetetu. U okviru ljudskog iskustva pojava može biti opažena, željena, zamišljena, anticipirana, prizvana iz sećanja itd. Stoga, prema filozofskoj literaturi, fenomen je ono što se prikazuje, tj. objekat koji se razotkriva (tj. predstavlja) našem iskustvu ${ }^{[1]}, a$ ne objekat onakav kakav možda jeste u stvarnosti. Fenomenologija, predstavlja zapravo grupu filozofskih doktrina koje dele slične

(a) pretpostavke od čega se svet sastoji (metafizički) i kako se može saznati (epistemološki), kao i

(b) strategije za opisivanje psihičkih pojava $^{[2]}$.

Cilj fenomenologije (u njenom izvornom smislu) jeste da "uhvati" iskustvene esencije, odnosno da opiše šta je ono što čini neodvojivu srž subjektivnog iskustva. Prema fenomenolozima, iskustvene esencije predstavljaju višu formu saznanja (nazivaju ih i epistemološke cigle), uz pomoć kojih fenomenolog može da rekonstruiše realnost ${ }^{[3]}$. Ukratko, može se reći da fenomenologija ispituje samu srž doživljaja, kao i način na koji se doživljaj može spoznati. Prema Beriosu (Berrios), termin fenomenologija se koristi u sledeća četiri značenja: (a) sinonim za "simptome i znake"; (b) termin koji se kristalizuje kroz hronologiju upotrebe različitih filozofa; (c) za označavanje kompleksnog filozofskog sistema koji je stvorio Edmund Huserl (Edmund Husserl, 1859-1938.), kao i fenomenološkog pokreta koji je potom usledio; i kao sinonim za (d) fenomenološku psihopatologiju ${ }^{[4]}$.

Prva upotreba termina, kao sinonim za "simptome i znake" je neodgovarajuća. Simptomi i znaci su termini koji se široko upotrebljavaju u medicinskim naukama uopšte, a odnose se na subjektivne doživljaje pacijenta (simptomi), odnosno pokazatelje bolesti koji su "spolja" vidljivi i samom ispitivaču (znaci). Sa filozofske tačke gledišta, ovako striktna podela (samo subjektivno ili samo objektivno) je veoma problematična. Očigledno je da je većina psihičkih znakova koji su ekspresivni (objektivni znaci) neodvojiva od subjektivne komponente (subjektivni simptomi) - npr. psihomotorna retardacija koja postoji u sadejstvu sa depresivnim raspoloženjem, slabljenjenje uticaja volje na ponašanje i sl. Ovaj, vrlo problematičan, aspekt upotrebe termina - simptomi i znaci, koji pretpostavlja dualističku filozofsku strukturu psihijatrije, neće biti 
dalje obrađivan, s obzirom da dualizam kao metafizička osnova u okviru psihijatrije ne predstavlja temu ovog rada. Međutim, neophodno je napomenuti, da "simptomi i znaci" nisu sinonim za fenomenologiju, s obzirom da fenomenologija ispituje srž iskustva, odn. doživljaja, koji se ne uklapa u idealne objektivno/ subjektivne kategorizacije koje su pretpostavljene u dualističkim konceptima medicinskih disciplina.

Druga upotreba termina podrazumeva definisanje fenomenologije kao sukcesivnu hronologiju stavova različitih filozofa. Problem ovakvog definisanja fenomenologije jeste izrazita heterogenost koja postoji prilikom upotrebe ovog termina u filozofskim delima. Naime, fenomen se javlja kao termin još kod Imanuela Kanta (Immanuel Kant) u 18. veku, ali Kantova upotreba reči fenomena nije povezana sa suštinskim značenjem koje dobija u okviru teorije fenomenologije koja je nastala tek u 19 . veku. Treća upotreba, koja podrazumeva označavanje filozofskog sistema Edmunda Huserla jeste, prema našem mišljenju, najvernije i najispravnije terminološko označavanje reči fenomenologija. Međutim, četvrta upotreba - uvođenje Huserlove fenomenologije (tačnije fenomenološkog prinicipa) u psihijatriju, od strane Karl Jaspersa (Karl Jaspers), vodi nas u terminološku upotrebu reči fenomenologija koja bi se preciznije mogla definisati kao - fenomenološka psihopatologija. Uzimajući u obzir treću i četvr- tu terminološku definiciju fenomenologije, u najopštijem smislu možemo reći da je fenomenologija - grupa filozofskih principa posvećenih sistematskoj analizi svesti i njenim objektima.

Osnovna pitanja na koja ovako definisana fenomenologija želi da odgovori su sledeća:

(a) kako se svest sa svojim sadržajima odnosi prema spoljnom svetu?

(b) Kako je moguće diferencirati mentalne fenomene od fizičkih (materijalnih) fenomena?

(c) Kako se mentalni fenomeni mogu razlikovati i diferencirati jedan od drugog? ${ }^{[2]}$

Kako bi razumeli nastanak ovih pitanja, neophodno je da razumemo i istorijski kontekst u kojima su se javljala. Smatra se da je fenomenologija prvobitno nastala kao reakcija na tzv. psihologizam 19. veka ${ }^{[4]}$. Psihologizam je podrazumevao shvatanje prema kojem se celokupni psihički život čoveka razume kao posledica kauzalnih dešavanja (slede neposredno jedna iz drugog). Ovakvo tumačenje predstavlja mehanicistički model, koji je preuzet iz prirodnih nauka (po uzoru na hemiju, biologiju i fiziku) primenjen na duševna zbivanja čoveka. $\mathrm{Na}$ taj način čovek, odnosno subjekat, se tretira kao objekat koji se analizira (na isti način kao što bi se tretirao i bilo koji drugi materijalni objekat, što je prema našem mišljenju, nepodobno).

Osnovni koncept na kome se zasniva fenomenologija jeste koncept intenci- 
onalnosti ${ }^{[5]}$. Intencionalnost podrazumeva sposobnost ljudskog uma da se odnosi prema objektima izvan sebe samog (npr. mišljenje koje je usmereno na objekat kao svoj cilj). To znači da postoji neodvojiva povezanost između psihičkog procesa koji doživljava i objekta koji je doživljen. Dakle, svest je uvek svest o nečemu, ili drugačije rečeno, svest o svojem ja se uvek može suprostaviti svesti o predmetu ${ }^{[3,6]}$. Stoga, opis realnosti je zapravo sadržaj svesti. Intencionalnost, na ovaj način definisana, jeste nešto što je svojstveno isključivo ljudskoj svesti. Ovo viđenje podrazumeva odbacivanje kartezijanskog dualizma, tj. podele na subjekat i objekat, kao i implicitnu podelu na dušu (ili psihu) i telo, koja je i dalje izrazito prevalentna u savremenoj medicini, uprkos propagiranju tzv. biopsihosocijalnog modela i "holističkog pristupa" pacijentu $^{[7]}$. Kao što je Merlo-Ponti (Merleau-Ponty), jedan od najistaknutijih fenomenologa objavio "čovek je uronjen u svet", odnosno, mi postojimo jedino posredstvom kompromisa sa svetom ${ }^{[8]}$.

Kao što je napomenuto, Edmund Huserl je idejni tvorac fenomenologije, ali se sa svojom filozofskom teorijom oslanjao na razmišljanja drugih mislilaca tog vremena, prvenstveno na Franca Brentana (Franz Brentano) i Vilhema Diltaja (Wilhelm Dilthey) ${ }^{[9,10]}$. Brentano i Diltaj su krajem XIX veka utvrdili da tadašnja analitička psihologija nije uspela da stvori adekvatan konceptualni mehanizam koji bi mogao da se "izbori” sa ljudskim umom. Stoga je Brentano govorio o neophodnosti da se kreiraju nove deskriptivne $\mathrm{i}$ analitičke metode koje će stvoriti osnov za novu "deskriptivnu psihologiju”. Diltaj je takođe oštro kritikovao psihologizam, smatrajući da je "psihologija objašnjavanja" preuzeta iz modela prirodnih nauka nepodobna za ljudski um. Oslanjajući se na ovu bazu, razvoj Huserlove fenomenološke misli je proticao kroz njegova dela Logička istraživanja (1903) i Ideja fenomenologije $(1913)^{[11,12]}$. Huserl se naročito interesovao za pitanje saznavanja univerzalnih istina o ljudskom iskustvu, kao i šta je ono što čini univerzalne esencije (po njegovom shvatanju, univerzalne esencije su cigle koje čine strukturu sveta). Edmund Huserl je bio plodan stvaralac koji je u toku svog, relativno dugog, životnog veka ostavio brojne zapise. Ukratko, njegov rad na konceptualizaciji fenomenologije se može podeliti na tri razdoblja. Najranije razdoblje karakterišu Huserlovi pokušaji da psihološki fundira filozofiju aritmetike. Srednji period je za psihijatriju najznačajniji, jer Huserl razvija srž ideje fenomenologije, kroz kulminaciju u pomenutim delima Logička istraživanja (1903) i Ideja fenomenologije (1913). Poslednje razdoblje čini uticajni otklon od fenomenologije Martina Hajdegera (Martin Heidegger), čiju vrhunac zapažamo kroz delo Kriza Evropskih nauka i transcendentalna fenomenologija (1936) ${ }^{[13]}$. Malo je poznato 
da je ovo delo prvi put štampano u Srbiji, u Beogradu, u okviru međunarodnog godišnjaka Philosophia. Na ovom mestu nećemo dalje govoriti o Huserlu jer sažimanje njegovog rada daleko prevazilazi obim ovog rada. Zainteresovan čitalac se upućuje na odgovarajuću filozofsku literaturu. U narednom delu ovog rada, pojasnićemo primenu fenomenološkog pristupa u psihopatologiji.

\section{Odnos fenomenologije i psihopatologije - fenomenološka psihopatologija}

Psihopatologija, prema Jaspersu, podrazumeva interdisciplinarnu nauku čiji je cilj razumevanje i objašnjavanje prirode patoloških pojava psihičkog života ${ }^{[6]}$. U okvirima psihopatologije govorimo o patološkim psihičkim pojavama koje su svesne. Stoga, psihopatologija zahteva metod uz pomoć kojeg se može izvršiti detaljna, sistematična analiza subjektiviteta, odn. doživljenog iskustva. Fenomenologija pruža metod koji to omogućava, a primena fenomenologije na psihopatološke pojave se naziva: fenomenološka psihopatologija. Zadatak fenomenološkog psihopatologa koji upotrebljava fenomenološke principe jeste da izvrši karakterizaciju psihopatološke pojave. Postupak karakterizacije podrazumeva artikulaciju iskustvene strukture koja je uslov postojanja psihopatološkog fenomena, a ne puko opisivanje iskustvene pojave ${ }^{[14]}$. Na primer, u psi- hopatološkoj eksploraciji pacijenta možemo govoriti o zaravnjenom afektu, tek kada uspostavimo osnovu da struktura takvog doživljaja svesti zauzima formu emocionalnog doživljaja.

Iz čega se, dakle, sastoji fenomenološki metod, primenjen na psihopatologiju? Podrazumeva:

(a) Sticanje jasne predstave, šta se dešava u umu pacijenta (Vergegenwärtigung),

(b) Izolaciju, odnosno demarkaciju (ograničavanje) psihičkih fenomena (Begrenzung),

(c) Formulaciju, odnosno deskripciju psihičkih fenomena (Beschreibung ${ }^{[3]}$.

Za primenu ovog postupka postoje određeni predulsovi, od kojih je osnovni - empatija. Prema Jaspersu, subjektivnim iskustvima ne pristupamo kroz čula, već putem "prenošenja sebe u psihu drugog čoveka"[6]. Dalje, treba podvući da cilj fenomenološke deskripcije jeste što detaljniji i obuhvatniji uvid u jedan slučaj (dubinski pristup). Takođe, cilj nije isključivo objašnjavanje nastanka psihičkog fenomena, već "hvatanje" procesa doživljavanja (ne samo rezulata doživljavanja). Stoga, fenomenologija ne posmatra subjektivno iskustvo kao "objekat" koji je potrebno opisati, već kao medijum koji dozvoljava svetu da se manifestuje. Imajući to u vidu, cilj nije objasniti sadržaj samog objekta, već formu i strukturu svesnog, doživljenog iskustva ${ }^{[15]}$. Fenomenološki pristup naglašava potrebu da se "zaroni” ispod 
površinskih bihejvioralnih ponašanja ili "zdravo-razumskih" simptomatskih deskripcija $^{[16]}$. Prema tome, fenomenološko poniranje u doživljaj pacijenta podrazumeva uživljavanje kliničara u razmenu sa pacijentom, istovremeno "stavljajući u zagradu" (odnosno "obustavljajući”) nozološki, psihološki ili patogenetski refleks ${ }^{[17,18]}$.

Jedan od načina konceptualizacije fenomenološkog pristupa jeste upoređivanje sa naučnim pristupom i interpretativnim pristupom ${ }^{[19]}$. Naučni pristup je princip preuzet iz prirodno-naučnih teorija. Opserviramo određene pojave, iz kojih izvlačimo zaključke (ako se dve pojave često javljaju zajedno, zaključujemo da su povezane). Stoga, naučni pristup (u uobičajenom smislu) se bavi merljivim performansama. Interpretativni pristup se bavi sadržajem pojava - poput psihoanalize - tumačimo one pojave koje se kod pacijenta javljaju, u kontekstu psihoanalitičke teorije koja se prethodno pokazala kao korisna. Za razliku od dva navedena pristupa, fenomenološki pristup, izveden iz filozofske tradicije se prvenstveno bavi formom iskustva. Na osnovu kontura forme, možemo grupisati fenomene, na osnovu onih aspekata koji su doživljeni kao tačke različitosti (halucinacije su perceptivne obmane, sumanute ideje su sadržajni poremećaji mišljenja i sl.).

Izvori podataka za fenomenološko-psihopatološku analizu predstavljaju

(a) pažljivo ispitivanje pacijenta, (b) udubljivanje u ponašanje pacijenta

(c) pregled napisanih opisa iskustva (dnevnici).

Psihopatološke fenomene koje opisujemo možemo podeliti na:

(a) fenomene koje poznajemo iz sopstvenog iskustva (npr. anksioznost),

(b) fenomene koje možemo razumeti kao prenaglašeno iskustvo, ili kombinaciju drugih iskustava (depresivno raspoloženje),

(c) fenomene koji nisu dostupni empatičnom razumevanju (npr. primarne sumanutosti u vidu ideja uticaja i sl. $)^{[6,20]}$.

Veoma je važno podvući da je fenomenološki pristup, odnosno fenomenološki stav nešto što se razvija i stiče. Jaspersovim rečima: "Kada smo bili deca, crtali smo stvari onako kako smo ih zamišljali, a ne onako kako smo ih videli; tako i kao psihopatolozi i psiholozi prolazimo kroz stadijum u kome formiramo sopstvene ideje [...] o psihičkim pojavama, da bi tek kasnije stekli uvid u to kakve ove pojave zaista jesu, bez predrasuda. I tako ovaj, fenomenološki stav, stiče se samo stalnim ponavljanjem napora i neprestanim prevazilaženjem predrasuda." $[6]$

\section{Karl Jaspers i njegov značaj za psihijatriju}

Uvođenje principa fenomenologije, odnosno fenomenološkog postupka u psihopatologiju je sistematično izvršio Karl Jaspers. Pored uticaja koji je izvršio na psihijatriju, on je takođe bio i 
istaknuti egzistencijalistički filozof. Najveći deo svog života i rada je proveo na Hajdelberškom Univerzitetu, gde je pod njegovim vođstvom nastala i tzv. Hajdelberška škola fenomenološke psihopato$\operatorname{logije} \mathrm{e}^{[21]}$.

Zašto je Karl Jasper značajan za psihijatriju? Ukratko, možemo reći da postoje bar četiri razloga:

(a) uvođenje fenomenološkog pristupa,

(b) uvođenje empirijskog ispitivanja subjektivnog iskustva,

(c) uvođenje principa razumevanja (Verstehen), pored principa objašnjavanja (Erklären)

(d) pozicioniranje fenomenološke psihopatologije u tadašnjem istorijskom trenutku ${ }^{[20]}$.

Uvođenjem fenomenološkog pristupa Jaspers razgraničava psihopatološke fenomene, na taj način stvarajući psihopatološku taksonomiju. Danas, kada govorimo o poremećaju mišljenja, ili poremećaju opažanja, govorimo o elementima ljudskog iskustva koje uočavamo na ovaj način upravo zbog nasleđa koje nam je ostavio Jaspers. Primera radi, u tekstovima iz XIX veka (kao i u tekstovima iz ranog XX veka) u kojima se opisuju doživljaji psihijatrijskih bolesnika, pod terminom koji danas obuhvata pojam sumanutosti (delusional, eng.) se može podrazumevati osoba koja ima poremećaj mišljenja (sumanuta ideacija), ili osoba koja doživljava akustičke halucinacije, ili pak osoba koja čiji doživljaj uključuje oba ova fenomena. Usled toga, nedostatak konzistentnog rečnika koji opisuje date fenomene (a koji je posledica nepostojanja adekvatnog konceptualnog okvira) je dovodio do nemogućnosti diskriminacije između ovih bitno različitih doživljaja ${ }^{[22,23]}$. Umesto "haosa" raznorodnih klasifikacija doživljaja, danas imamo određeni "logički" sistem kojim možemo da se vodimo prilikom izražavanja i opisivanja psihopatoloških pojava.

Uvođenjem empirijskog ispitivanja subjektivnih iskustava ona se više ne zapostavljaju zbog "nepouzdanosti". Ranije, jedna od domantnih tendencija kliničara je bila - isključivanje pacijenta kao posmatrača ili subjekta koji ima bilo kakve veze sa sopstvenim fenomenima. Prednost se davala opservaciji kliničara, uz naglašavanje učestalosti i izraženosti određenih pojava, pogrešno verujući da su to jedine "objektivne činjenice" na osnovu kojih možemo pouzdano da nešto zaključimo o psihijatrijskoj bolesti. Naspram toga, teško merljivi aspekti subjektivnosti su se zanemarivali, npr. smisao koji pacijent pridaje svom doživljaju. Jaspers vraća značaj ličnog, subjektivnog odnosa pacijenta sa psihopatološkom pojavom u fokus psihijatrije stvarajući osnovu za mnoge, kasnije nastale, koncepte koji su važni za savremenu psihijatriju (personalizovana terapija, važnost kvaliteta života, pacijent kao saradnik u lečenju).

Prateći rad Diltaja, Jaspers je uveo 
u psihopatologiju čuvenu distinkciju između objašnjavanja (Erklären) i razumevanja (Verstehen). Ukratko, metodom objšanjavanja pristupamo psihičkom životu u poput priordnog naučnika, tražeći kauzalne veze između različitih psihičkih stanja (empirijska logika). Međutim varijeteti ljudskog iskustva često ne podrazumevaju jasan međusbni kauzalitet. Usled toga, uz empatijsko uživljavanje, upotrebljavamo metod razumevanja, kojim rekonsturišemo doživljaje pacijenta na način koji je nama razumljiv (empatijska logika) ${ }^{[18]}$.

Konačno, Jaspers izdvaja filozofsko-fenomenološki metod u vremenu kolizije dve inkompatibilne stuje - psihoanalize i "mitologije mozga" ${ }^{[24,25]}$. Za razumevanje Jaspersovog doprinosa, neophodno je razumeti i ovaj, istorijski kontekst njegovog stvaralaštva. Početkom dvadesetog veka, širom oblasti psihijatrije dominirale su dve struje - psihoanaliza i biologizam (takozvana "mitologija mozga") ${ }^{[26,27]}$. Jaspersovi savremenici (i pretpostavljeni) su bili istaknuti intelektualci koji su obeležili neuronauke i neurobiologiju: Franc Nisl, Alojz Alchajmer, Karl Vernike ${ }^{[28]}$. Istovremeno, tokom tog doba, psihoanaliza Sigmunda Frojda je postala prepoznata u stručnoj javnosti i ubrzano je zauzimala centralno mesto u razmišljanju o psihičkim tegobama. Izražena heterogenost ideja o tome kako pristupiti pacijentima, kao i sklonost dogmatizmu nekih od gore navedenih mislilaca nisu omogućavali odgovarajuću integraciju. Upotrebom fenomenološkog metoda, kao i pratećeg pluralističkog principa izloženog u fundamentalnom delu Opšta psihopatologija (1913), Jaspers je omogućio sveobuhvatno sagledavanje ovih raznorodnih saznanja. Opšta psihopatologija je jedno od najzačajnijih dela u psihijatriji uopšte, nazivana i "intelektualnom mapom psihijatrije"[29]. Jaspers kroz Opštu psihopatologiju pruža filozofsku osnovu psihijatriji, baveći se epistemološkim pitanjima i skicirajući fenomenološki pristup psihopatologiji. Njegovim rečima, svrha Opšte psihopatologije predstavlja: "razumevanje konceptualne osnove onoga što radimo u psihijatriji”[6].

\section{Fenomenologija u praksi, fenomenološka psihopatologija danas}

U ovom radu smo se fokusirali na upotrebu fenomenologije $\mathrm{u}$ psihopatologiji u kontekstu psihijatrijskog intervjuisanja, tj. prvenstveno na metod razjašnjavanja subjektivnih iskustva pacijenata. Potrebno je naglasiti da primena fenomenologije u psihijatriji predstavlja izuzetno široku oblast, koja nije samo ograničena na opisivanje patološkog iskustva. Naime, s obzirom da psihijatrija predstavlja disciplinu koja se zasniva na brojnim filozofskim pitanjima (npr. šta su sumanutosti, da li se sa sumanutim osobama može empatisati; na kojim osnovama se zasniva koncept psi- 
hičkog poremećaja i sl.), na ova pitanja fenomenologija može pružiti određene odgovore. Takođe, nezanemarljiv je odnos fenomenologije sa neurobiologijom. Prema mišljenju čuvenog fenomenologa Fransiska Varele (Francisco Varela), fenomenološka analiza može oblikovati empirijska (neurobiološka) istraživanja svesti, da bi recipročno, empirijski nalazi vodili i obilkovali fenomenološka istraživanja ${ }^{[1,30]}$.

Fenomenološka psihopatologija je doživela "renesansu" tokom poslednjih nekoliko decenija, naročito u istraživanjima vezanim za doživljaje u shizofreniji. Kao odgovor na potrebe istraživača i kliničara, razvijeno je nekoliko semi-strukturisanih intervjua, zasnovanih na fenomenološkoj psihopatologiji. Oni se orijentišu na doživljajne stukture kao što su: isksutvena demarkacija, egzistencijalna reorijentacija, tok svesti, osećaj sopstva i sl. ${ }^{[31,32]}$

Danas, radovi i eseji o fenomenološkoj psihopatologiji pokrivaju raznolike teme, poput poremećaja doživljaja prisutnih u depresiji ${ }^{[33]}$, promena osećaja sopstva u paničnom poremećaju ${ }^{[34]}$, ispitivanja sličnosti i razlika između mističkih stanja i psihoze ${ }^{[35]}$, otelotvorenje u poremećajima ishrane ${ }^{[36,37]}$. Neka od značajnih imena u savremenoj fenomenologiji su: Louis Sass, Josef Parnas, Matthew Ratcliffe, Giovanni Stanghellini, Mathew Broome, Thomas Fuchs. Pored navedenih upitnika, neki od resursa ka kojima usmeravamo zainteresovanog čitaoca su: The Oxford Handbook of Phenomenological Psychopathology ${ }^{[14]}$; The Maudsley Reader in Phenomenological Psychiatry ${ }^{[38]}$; časopis Philosophy, Psychiatry, \& Psychology; časopis Journal of Phenomenological Psychology; časopis Psychopathology; časopis Consciousness and Cognition; časopis Phenomenology and the Cognitive Science.

\section{ZAKLJUČAK}

Stvaranje i primena fenomenološkog metoda u psihopatologiji je jedno od najznačajnijih dostignuća psihijatrije XX veka i uvod u mnoge aktuelne promene kada je u pitanju nozologija i dijagnostka psihijatrijskih poremećaja. Imajući u vidu da se način sagledavanja psihijatrijskih poremećaja kroz vekove menjao, više nego što je to slučaj sa bilo kojom drugom granom medicine, zahvalni smo što preispitujući stare postulate kroz savremena, molekularna saznanja imamo priliku za unapređenje dijagnostike, lečenja i dugoročne prognoze poremećaja sa kojima se bore oboleli od duševnih bolesti. Neophodno je da stremimo ka sagledavanju i razumevanju doživljenog iskustva pacijenta, ne samo da se zadovoljavamo uopštenim i površnim objašnjenjima o uzrocima psihopatoloških fenomena jer:

"Čovek je uvek nešto više od onog što on o sebi zna i može da zna."

K. Jaspers, 1913. 


\section{PHENOMENOLOGY, PSYCHOPATHOLOGY AND \\ PHENOMENOLOGICAL PSYCHOPATHOLOGY}

\section{Stefan Jerotic ${ }^{1}$, Maja Pantovic-Stefanovic ${ }^{1,2}$}

1 Clinic for Psychiatry,

The University Clinical Centre of Serbia,

Belgrade, Serbia

2 Faculty of Medicine, University of Belgrade, Belgrade, Serbia

doi: $10.5937 /$ engrami42-32891 submitted: 2021/06/24 accepted: $2021 / 08 / 20$ online published: $2021 / 08 / 30$

\section{Abstract}

The observation, description and definition of the structure of psychopathological phenomena make up the foundation of clinical psychiatry. Phenomenology can be defined as a group of philosophical principles that are dedicated to the systematic analysis of consciousness and its objects. Phenomenological psychopathology is the application of phenomenological principles to psychopathology. The goal of phenomenological psychopathology is to make explicit the subtle structures of pathological experience. Thus, the use of the phenomenological method enables us to disclose the indistinct or neglected psychopathological phenomena. It allows us to systematically construct a psychopathological taxonomy. This paper defines and summarizes the following topics: (1) phenomenology as a set of philosophical doctrines; (2) phenomenological 
psychopathology and its application in clinical work; (3) the significance of Karl Jaspers for phenomenological psychopathology and psychiatry; (4) contemporary trajectories of phenomenological psychopathology. A comprehensive understanding of the concept of phenomenological psychopathology is a prerequisite for the precise understanding of the subjective experience of the psychiatric patient.

Keywords: phenomenology, psychopathology, Karl Jaspers

\section{LITERATURA / LITERATURE}

1. Zahavi D. Phenomenology: the basics. Routledge; 2018.

2. Berrios GE. What is phenomenology? A review. J R Soc Med. 1989;82(7):425-8.

3. Stepanovic S. Filozofske pretpostavke Jaspersove Opšte psihopatologije. Filozofski Fakultet, Univerzitet u Beogradu; 2005.

4. Berrios GE. Phenomenology, psychopathology and Jaspers: a conceptual history. Hist Psychiatry. 1992;3(11):303-27.

5. Sartre J-P. Intentionality: a fundamental idea of Husserl's phenomenology. J Br Soc Phenomenol. 1970;1(2):4-5.

6. Jaspers K. Opšta psihopatologija. Beglrade: Prosveta, Savremena administracija; $1978.14 \mathrm{p}$.

7. Miresco MJ, Kirmayer LJ. The persistence of mind-brain dualism in psychiatric reasoning about clinical scenarios. Am J Psychiatry. 2006;163(5):913-8.

8. Merlo-Ponti M. Fenomenologija percepcije. Sarajevo: Veselin Masleša; 1978.

9. Tillman MK. Dilthey and Husserl. J Br Soc Phenomenol. 1976;7(2):123-30.

10. Morrison JC. Husserl and Brentano on intentionality. Philos Phenomenol Res. 1970;31(1):27-46.

11. Huserl E. Ideja fenomenologije. Beograd: Bigz; 1975.

12. Huserl E. Logička istraživanja. Zagreb: Breza; 2005.

13. Huserl E. Kriza evropskih nauka. Gornji Milanovic: Decije novine; 1991.

14. Stanghellini G, Broome M, Fernandez AV, Raballo A. The Oxford handbook of phenomenological psychopathology. Oxford University Press, USA; 2019.

15. Fuchs T. Phenomenology and 
psychopathology. In: Handbook of phenomenology and cognitive science.

Springer; 2010. p. 546-73.

16. Sass L, Parnas J, Zahavi D.

Phenomenological psychopathology and schizophrenia: contemporary approaches and misunderstandings. Philos Psychiatry, Psychol. 2011;18(1):1-23.

17. Parnas J, Sass L, Zahavi D.

Phenomenology and psychopathology.

Philos Psychiatry, Psychol. 2011; 18(1):37-9.

18. Jerotic S. Prejudices in the psychopathologist: Karl Jaspers' heritage. Eur Arch Psychiatry Clin Neurosci. 2021;1-8.

19. Beumont PJ V. Phenomenology and the history of psychiatry. Aust N Z J Psychiatry. 1992;26(4):532-45.

20. Telles-Correia D, Saraiva S, Marques JG. Jaspers' Phenomenology. Folia Med (Plovdiv). 2018;60(3):373-80.

21. Janzarik W, Viviani R, Berrios GE. Jaspers, Kurt Schneider and the Heidelberg school of psychiatry. Hist Psychiatry. 1998;9(34):241-52.

22. Ey H. Esquirol et le problem des hallucinations. Evol Psychiatr. 1939;1:2144.

23. Telles-Correia D, Moreira AL, Goncalves JS. Hallucinations and related conceptstheir conceptual background. Front Psychol. 2015;6:991.

24. Doerr-Zegers O, Pelegrina-Cetrán H. Karl Jaspers' General Psychopatholgy in the framework of clinical practice. In: Stanghellini G, Fuchs T, editors. One century of Karl Jaspers' general psychopathology. 2013. p. 57-75.

25. Jaspers $K$. The phenomenological approach in psychopathology. $\mathrm{Br} \mathrm{J}$ Psychiatry. 1968;114(516):1313-23.
26. Bormuth M. Karl Jaspers. In: Stanghellini G, Broome M, Fernandez AV, Fusar-Poli $P$, Raballo A, Rosfort R, editors. The Oxford Handbook of Phenomenological Psychopathology. Oxford University Press; 2019.

27. Broome M. Jaspers and neuroscinece. In: Stanghellini G, Fuchs T, editors. One century of Karl Jaspers' general psychopathology. 2013. p. 121-32.

28. Häfner H. Descriptive psychopathology, phenomenology, and the legacy of Karl Jaspers. Dialogues Clin Neurosci. 2015 Mar;17(1):19-29.

29. Ghaemi SN. The concepts of psychiatry: a pluralistic approach to the mind and mental illness. JHU Press; 2003.

30. Varela FJ. Neurophenomenology: A methodological remedy for the hard problem. J Conscious Stud. 1996;3(4):330-49.

31. Parnas J, Møller P, Kircher T, Thalbitzer J, Jansson L, Handest P, et al. EASE: examination of anomalous self-experience. Psychopathology. 2005;38(5):236.

32. Sass L, Pienkos E, Skodlar B, Stanghellini G, Fuchs T, Parnas J, et al. EAWE: Examination of Anomalous World Experience. Psychopathology. 2017;

33. Ratcliffe $M$. The phenomenology of depression and the nature of empathy. Med Heal Care Philos. 2014;17(2):269-80.

34. Madeira L, Carmenates S, Costa C, Linhares L, Stanghellini G, Figueira $M L$, et al. Basic self-disturbances beyond schizophrenia: discrepancies and affinities in panic disorder-an empirical clinical study. Psychopathology. 2017;50(2):157-68.

35. Parnas J, Henriksen MG. Mysticism and schizophrenia: A phenomenological 
exploration of the structure of

consciousness in the schizophrenia

spectrum disorders. Conscious Cogn.

2016;43:75-88.

36. Williams S, Reid M. 'It's like there are two people in my head': A phenomenological exploration of anorexia nervosa and its relationship to the self. Psychol Health. 2012;27(7):798-815.

37. Burkitt I, Sanz J. Embodiment, lived experience and anorexia: the contribution of phenomenology to a critical therapeutic approach. Athenea Digit Rev Pensam e Investig Soc. 2001;38-52.

38. Broome MR, Owen GS, Stringaris A. The Maudsley reader in phenomenological psychiatry. Cambridge University Press; 2012.

Dr Stefan Jerotić, Klinika za psihijatriju, Univerzitetski klinički centar Srbije, Pasterova 2, 11000 Beograd stefan.jerotic@gmail.com 